\title{
Carotid sheath 'intubation' during an emergency surgical cricothyroidotomy
}

\author{
Tricia Cheah, ${ }^{1,2}$ Jennifer $\mathrm{F} \mathrm{Ha}^{3,4}$
}

\begin{abstract}
${ }^{1}$ Sir Charles Gairdner Hospital, Nedlands, Western Australia, Australia

${ }^{2}$ Fiona Stanley Hospital, Murdoch, Western Australia, Australia

${ }^{3}$ Department of

Otorhinolaryngology Head and Neck Surgery, Sir Charles

Gairdner Hospital, Nedlands, Western Australia, Australia

${ }^{4}$ Department of Paediatric Otorhinolaryngology Head and Neck Surgery, VA Ann Arbor Healthcare System, Ann Arbor, Michigan, USA
\end{abstract}

\section{Correspondence to} Dr Tricia Cheah, tricia.cheah@gmail.com

Accepted 11 May 2016

\section{DESCRIPTION}

A previously well 62-year-old man was admitted to a regional hospital, with scalp swelling, headache, fever and rigors following a scalp injury 3 weeks prior. He developed meningism with progressive left-sided hemiparesis, and had a focal seizure on his fourth day of admission. Following a generalised seizure on day 5 of admission, he was referred to a metropolitan tertiary hospital, for neurosurgical intervention of an extradural and subdural empyema.

Prior to transfer by the Royal Flying Doctor Service, he required a definitive airway and was taken to the emergency department, for sedation and intubation. Two unsuccessful attempts at orotracheal intubation were performed by the emergency physician, followed by successful placement of a laryngeal mask airway (LMA). The decision to attempt surgical cricothyroidotomy was made as the LMA did not suffice as a definitive airway. A vertical incision in the skin of the anterior neck exposed what was believed to be the cricothyroid membrane (CTM). Three attempts at insertion of an endotracheal tube (ETT) were made via this landmark with the third appearing to enter the trachea. However, on removal of the LMA, the patient became hypoxic and cyanotic, and was difficult to ventilate through the surgical airway.

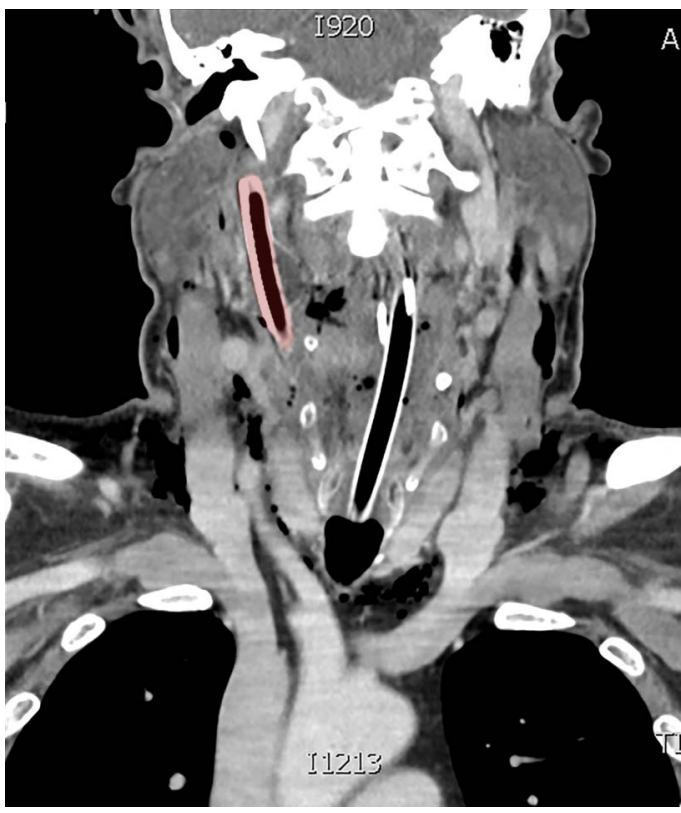

To cite: Cheah T, Ha JF BMJ Case Rep Published online: [please include Day Month Year] doi:10.1136/ bcr-2016-214898
Figure 1 CT of the neck showing the distal end of the extra-tracheal ETT directed superiorly, posteriorly and to the right. A small haematoma is seen surrounding the ETT at the level of the right parapharyngeal space. ETT, endotracheal tube.
Subcutaneous emphysema was also identified around the neck and face. The LMA was reinserted and the ETT sutured in place.

Following arrival to intensive care at the tertiary hospital, bronchoscopy demonstrated traumatised and oedematous cords with confirmation that the ETT was not within the trachea. The LMA was removed and the patient successfully reintubated by the Intensive Care Registrar. The Ear, Nose and Throat Registrar was called for consultation and noted intermittent bleeding from the misplaced ETT, which raised suspicion of a paratracheal vascular injury. A CT scan with contrast revealed the ETT coursing superiorly, posteriorly and to the right, with its tip abutting the right carotid sheath inferior to the skull base (figure 1). The tube bordered the proximal cervical internal carotid artery with the tip distorting the internal jugular vein (figure 2). Extensive surgical emphysema extending into the superior mediastinum, supraclavicular fossae and posterior triangles was also shown.

Surgical exploration of the false tract made by the misplaced ETT revealed an initial erroneous incision in the thyrohyoid membrane instead of the CTM (figure 3). There was entry into the carotid sheath, but no identified injury to its contents. Laceration of the anterior jugular vein was

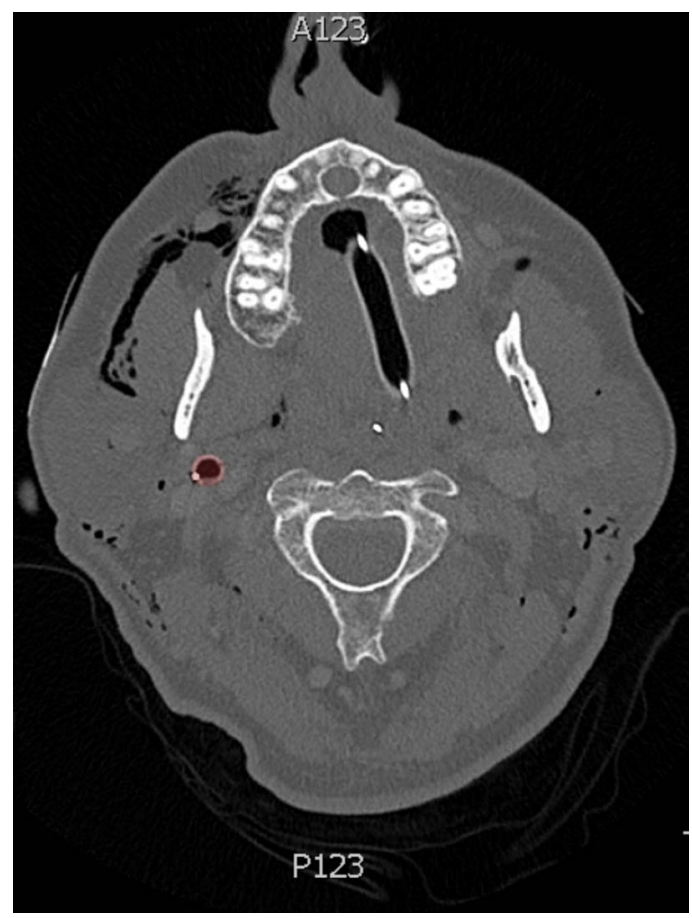

Figure 2 Although not a dedicated vascular CT, this transverse section of the neck at C2 demonstrates the ETT within the anterior right carotid sheath with distortion of the jugular vein. ETT, endotracheal tube. 


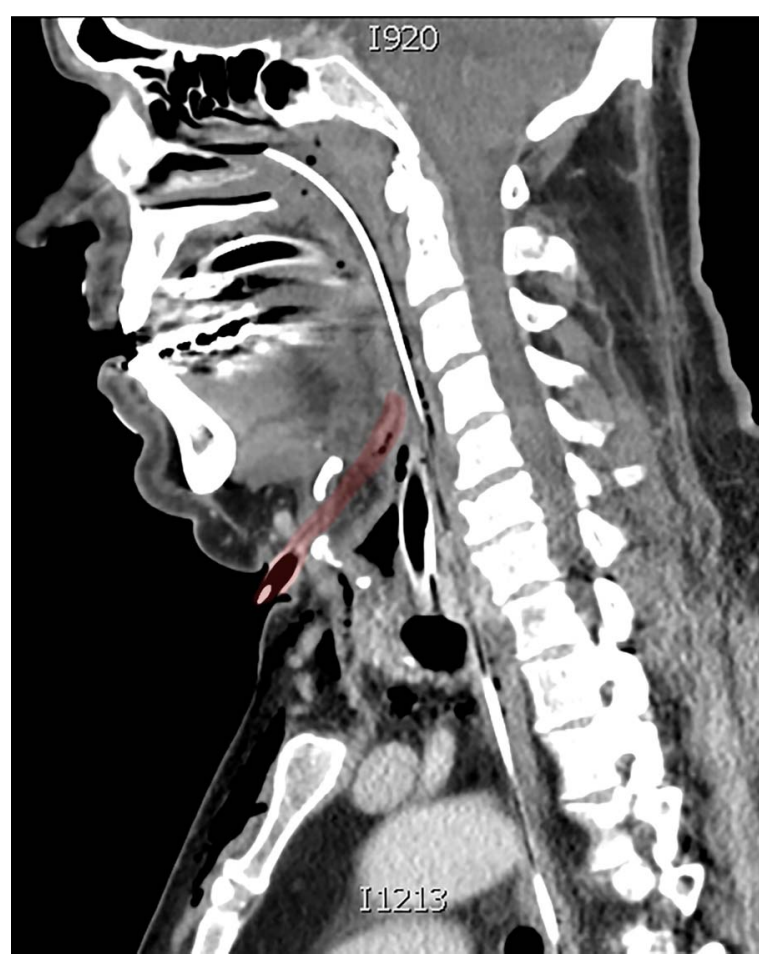

Figure 3 ETT visualised passing from the skin between the hyoid bone and calcified thyroid cartilage in keeping with surgical finding of mistaken identification of the thyrohyoid membrane for the CTM. CTM, cricothyroid membrane; ETT, endotracheal tube.

identified as the source of intermittent bleeding, and ligated. The patient subsequently underwent craniotomy and evacuation of the empyema, making a good neurological recovery.

Contributors TC wrote and submitted the manuscript for publication. JFH provided care for the patient during admission and supervised the writing of the manuscript.

Competing interests None declared.

Patient consent Obtained.

Provenance and peer review Not commissioned; externally peer reviewed.

\section{Learning points}

- The major caveat to the cricothyroidotomy is the correct identification of important surface landmarks. ${ }^{1}$ The thyroid notch can be palpated in most, and further identification of the cricoid cartilage, hyoid bone and cricothyroid membrane (CTM) are recommended for successful placement. ${ }^{1} \mathrm{~A}$ midline vertical incision can be made for ease of re-identification of these structures prior to horizontal incision through the CTM. ${ }^{1}$

- The CTM is the ideal area for introduction of an emergency surgical airway as it sits below the level of the vocal cords, thus reducing the risk of damage to these delicate structures. $^{2}$ The cricoid cartilage also forms a circumferential cartilaginous ring around the trachea thereby offering some protection to the oesophagus posteriorly. ${ }^{2}$ In comparison, the thyrohyoid membrane is located more cephalad and attempts at passage of an endotracheal tube (ETT) at this location can damage the cords, epiglottis or the internal laryngeal nerve and superior laryngeal vessels that pierce the membrane laterally. ${ }^{2}$ This is not an uncommon pitfall, as highlighted by a retrospective review by McGill et al, ${ }^{1}$ in which four of five misplaced tubes during cricothyroidotomy were through the thyrohyoid membrane.

- Formation of a false extra-tracheal tract is a recognised early complication of cricothyroidotomy. ${ }^{3}$ This case clearly demonstrates the close relations of the major paratracheal neurovasculature, as well as the signs of a misplaced ETT including difficulty with oxygenation and development of surgical emphysema on attempts to ventilate the patient.

\section{REFERENCES}

1 McGill J, Clinton JE, Ruiz E. Cricothyrotomy in the emergency department. Ann Emerg Med 1982;11:361-4

2 Boon JM, Abrahams PH, Meiring JH, et al. Cricothyroidotomy: a clinical anatomy review. Clin Anat 2004;17:478-86.

3 Gillespie MB, Eisele DW. Outcomes of emergency surgical airway procedures in a hospital-wide setting. Laryngoscope 1999;109:1766-9.

Copyright 2016 BMJ Publishing Group. All rights reserved. For permission to reuse any of this content visit

http://group.bmi.com/group/rights-licensing/permissions.

BMJ Case Report Fellows may re-use this article for personal use and teaching without any further permission.

Become a Fellow of BMJ Case Reports today and you can:

- Submit as many cases as you like

- Enjoy fast sympathetic peer review and rapid publication of accepted articles

- Access all the published articles

- Re-use any of the published material for personal use and teaching without further permission

For information on Institutional Fellowships contact consortiasales@bmjgroup.com

Visit casereports.bmj.com for more articles like this and to become a Fellow 